\title{
PLACENTAL DIAMETER AND THICKNESS AND NUMBER OF COTYLEDONS IN MILD AND SEVERE PREGNANCY INDUCED HYPERTENSIVE WOMEN VERSUS NORMOTENSIVE WOMEN OF DISTRICT D.I.KHAN, PAKISTAN
}

\author{
Shehla Aman', Sarah Arif², Amir Amanullah', Jamshed Khan ${ }^{3}$, Sarah Yunus', Usman Ullah" \\ Departments of ${ }^{1}$ Anatomy \& ${ }^{2}$ Pathology, Gomal Medical College, D.I.Khan, Departments of Anatomy, ${ }^{3}$ Loralai \\ Medical College \& ${ }^{4}$ Gajju Khan Medical College, Swabi, Pakistan
}

\begin{abstract}
Background: Pregnancy induced hypertension $(\mathrm{PIH})$ adversely affects the development of placenta and growth of fetus. The objectives of this study were to compare the placental diameter, placental thickness and number of cotyledons in mild PIH and severe PIH women versus normotensive women of District D.I.Khan, Pakistan.

Material \& Methods: This comparative cross-sectional study was conducted in Department of Anatomy, Gomal Medical College, D.I.Khan, Pakistan from January to October 2014. Three samples were selected; each of size 50, group 1 normotensive/ control, group 2 with mild $\mathrm{PIH}$ and group 3 with severe PIH. Three research variables; placental diameter $(\mathrm{cm})$, thickness $(\mathrm{mm})$ and number of cotyledons were measured on ratio scale for three groups. Descriptive analysis included mean \pm SD with 95\% confidence intervals for each group separately. With three groups on ratio data, one way-ANOVA test was applied to see significance of difference between three groups. Post hoc Dunnett's t test was applied at alpha 0.05 to see difference of mild PIH group 2 to normotensive/ control group 1 and of severe PIH group 3 to normotensive/ control group 1separately.

Results: Mean placental diameter was $18.28 \pm 2.15,16.57 \pm 1.94$ and $16.18 \pm 1.75 \mathrm{~cm}$ and mean placental thickness was $19.33 \pm 3.70,19.18 \pm 2.78$ and $17.60 \pm 3.52 \mathrm{~mm}$ in group 1,2 and 3 respectively. Mean number of cotyledons was $14.42 \pm 2.25,14.08 \pm 2.30$ and $13.16 \pm 2.15$ in group 1,2 , and 3 respectively. Placental diameter was statistically significantly lower in group $2(p=<.00001)$ and $3(p=<.00001)$ than group 1 . Placental thickness in group $2(p=.957)$ was similar to group 1 , while in group $3(p=<.019)$ it was lower than group 1. Number of cotyledons in group $2(p=.666)$ was similar to group 1 , while in group $3(p=<.011)$ it was lower than group 1.

Conclusion: In mild pregnancy induced hypertension (PIH), placental diameter was lower than normotensives, while placental thickness and number of cotyledons were similar to normotensives. In severe PIH, placental diameter, placental thickness and number of cotyledons were all lower than normotensives. It is concluded that in mild $\mathrm{PIH}$, the development of placenta is mildly affected, while in severe $\mathrm{PIH}$, the development of placenta is severely affected.
\end{abstract}

KEY WORDS: Placenta; Morphology; Hypertension; Pregnancy Induced Hypertension Pregnancy; Women; Cotyledons; Maternal Mortality.

Cite as: Aman S, Arif S, Amanullah A, Khan J, Yunus S, Ullah U. Placental diameter and thickness and number of cotyledons in mild and severe pregnancy induced hypertensive women versus normotensive women of district D.I.Khan, Pakistan. Gomal J Med Sci 2020 Oct-Dec; 18(4):156-63. https://doi.org/10.46903/gjms/18.04.839

\section{Corresponding Author:}

Dr. Shehla Aman

Assistant Professor, Department of Anatomy Gomal Medical College, D.I.Khan, Pakistan

E-mail: shehlakhan7272@gmail.com

Date Submitted: $\quad$ 05-07-2019

Date Revised: $\quad 18-04-2020$

Date Accepted:
$12-08-2020$

\section{INTRODUCTION}

1.1 Background: For development and survival of embryo and successful outcome of pregnancy, placental development and functions are critical. ${ }^{1,2}$ Pregnancy induced hypertension $(\mathrm{PIH})$ is regarded as a risk factor in pregnancy and it grossly affects the development of placenta and growth of fetus. It has been found that hypertension during preg- 
nancy causes nearly $12 \%$ of maternal deaths in the world. ${ }^{3,4}$ In United states it accounts for $15.9 \%$ maternal mortality. ${ }^{5}$ Every year 585,000 maternal deaths occur due to complications of pregnancy and labor like IUGR and intra uterine death. More than 99\% deaths occur in the less well developed countries. ${ }^{3,6}$

Overall incidence of PIH has been reported as $9 \%$ in Pakistan. A study conducted at Peshawar, Pakistan revealed a prevalence rate of $1.65 \%$ in year 2003 . Another study conducted in Abbottabad, Pakistan revealed that hypertension in some form effects 15$20 \%$ of pregnancies and a frequency of eclampsia is about $3 / 100 .^{7}$

About $75 \%$ population is living in rural areas in Pakistan where proper facilities for antenatal care are not available. Most of these patients present with complications of $\mathrm{PIH}$ at tertiary care hospitals. ${ }^{8}$ Placenta is also affected by complications of pregnancy and shows an adaptive response to prevent diseases of fetus. These disease processes result in changes in gross morphology of placenta. ${ }^{9}$

The objectives of this study were to compare the placental diameter, placental thickness and number of cotyledons in mild PIH and severe PIH women versus normotensive women of District D.I.Khan, Pakistan.

1.2 Research Problems (RPs), Knowledge Gaps (KGs), Research Questions (RQs) \& Rationale of the study

Our six RPs were unawareness of difference of placental diameter, placental thickness and number of cotyledons respectively in mild pregnancy induced hypertension $(\mathrm{PIH})$ and severe $\mathrm{PIH}$ women versus normotensive women of District D.I.Khan, Pakistan.

No relevant studies could be retrieved regarding these six RPs. These are our six KGs.

What would be the difference of placental diameter, placental thickness and number of cotyledons respectively in mild $\mathrm{PIH}$ and severe PIH women versus normotensive women of District D.I.Khan, Pakistan? These were our six RQs.

To answer these six RQs, to fill these six KGs and to solve these six RPs would be the rationale of our study.

\subsection{Research Objectives}

RO 1-2: To determine the difference of placental diameter in mild pregnancy induced hypertension (PIH) and severe PIH women respectively versus normotensive women of District D.I.Khan, Pakistan.

RO 3-4: To determine the difference of placental thickness in mild PIH and severe PIH women respectively versus normotensive women of District D.I.Khan, Pakistan.

RO 5-6: To determine the difference of number of placental cotyledons in mild PIH and severe PIH women respectively versus normotensive women of District D.I.Khan, Pakistan.

\subsection{Research (Null) Hypotheses:}

$\mathbf{H}_{01}$ : Placental diameter in mild pregnancy induced hypertension $(\mathrm{PIH})$ women is same as in normotensive women of District D.I.Khan, Pakistan. (RQ1) $\mathbf{H}_{02}$ : Placental diameter in severe PIH women is same as in normotensive women of District D.I.Khan, Pakistan. (RQ1)

$\mathbf{H}_{03}$ : Placental thickness in mild PIH women is same as in normotensive women of District D.I.Khan, Pakistan. (RQ2)

$\mathbf{H}_{04}$ : Placental thickness in severe PIH women is same as in normotensive women of District D.I.Khan, Pakistan. (RQ2)

$\mathbf{H}_{05}$ : Number of placental cotyledons in mild PIH women is same as in normotensive women of District D.I.Khan, Pakistan. (RQ3)

$\mathbf{H}_{06}$ : Number of placental cotyledons in severe PIH women is same as in normotensive women of District D.I.Khan, Pakistan. (RQ3)

1.5 Operational definitions

Pregnancy Induced Hypertension: $\mathrm{PIH}$ is the development of hypertension after $20^{\text {th }}$ week of pregnancy in previously normotensive female with no significantly detected proteinurea. ${ }^{10}$

Mild Hypertension: Mild PIH is diastolic B.P 90-99 $\mathrm{mmHg}$, and/or systolic B.P 140-149 mmHg. ${ }^{11}$

Moderate Hypertension: Moderate PIH is diastolic B.P 100-109 mm Hg and/or systolic B.P 150-159 mmHg. ${ }^{11}$

Severe Hypertension: Severe PIH is diastolic B.P $110 \mathrm{mmHg}$ or greater and/or systolic B.P $160 \mathrm{mmHg}$ or greater. ${ }^{11}$

\section{MATERIAL AND METHODS}

2.1 Design, Duration \& Setting: This comparative cross-sectional study was carried out at the Department of Anatomy, Gomal Medical College, D.I.Khan, Pakistan from January 2014 to October 2014. The specimens were collected from labor room of $\mathrm{DHQ}$ Teaching Hospital, D.I.Khan.

\subsection{Population, Sample size, Technique \& Selec-} tion:

D.I.Khan is the southern district of Khyber Pakhtunkhwa province of Pakistan. Its population was 852,995 as per 1998 census. For 2014, its population was assumed to be around 14 million. Assuming $48.8 \%$ share of women, the population of women came to be $677,600(48.4 * 1,400,000 / 100=677,600)$. Assuming $45.67 \%$ women in the reproductive age (15-49 years), the count came to be 309,460 $(45.67 * 677,600 / 100=309,459.92)$. This is our population at risk for pregnancy induced hypertension (PIH) and thus for sample calculation. With 309,460 population, $1.81 \%$ margin of error, $95 \%$ confidence 
interval, $1.2922 \%^{12}$ assumed prevalence of $\mathrm{PIH}$ $\left(26^{*} 100 / 2,012=1.2922\right)$ in this population, the sample size was calculated to be 150 , using Raosoft online sample size calculator. ${ }^{13}$

Three sub-samples were selected based on their antenatal record; each of size 50, group 1 normotensive/ control, group 2 with mild PIH and group 3 with severe $\mathrm{PIH}$. Non-probability consecutive sampling technique was applied.

Patients with moderate pregnancy induced hypertension, essential hypertension, chronic renal disease, chronic liver disease, diabetes mellitus, gestational diabetes, any kind of tobacco smoking, twin pregnancy, incomplete delivery of placenta, abruptio placentae, placenta previa, any other convulsive disorder, any type of congenital abnormalities, hydrops fetalis and intra uterine death were excluded.

2.3 Conduct of Procedure: Placentae were collected with informed consent from patients from labor room immediately after delivery and preserved in $10 \%$ formalin. Samples were shifted to Department of Anatomy, Gomal Medical College, D.I.Khan for inspection. Each placenta was placed in a flat tray, washed with normal saline to remove blood clots, gently pressed to remove extra blood and mopped with cotton. Umbilical cord was cut nearest to its insertion point on placenta, and membranes were trimmed at the margins.

Maximum diameter of the placenta was measured in centimeters with the help of metallic scale. At right angle to the first measurement, a second maximum diameter was taken and mean of the two was considered as diameter of placenta.

Placenta was placed on its fetal surface. It was arbitrarily divided into three equal size zones by drawing two circles on its maternal side so that radius of placenta was cut into three equal parts. Thickness was measured by a long needle pierced into placenta and embedded part was measured. One thickness was measured from the center of the circle, two readings from the middle zone and two readings from the peripheral zone were measured. Mean of the five readings was taken as thickness in millimeters.

Each placenta was placed on both hands and gentle pressure applied by thumbs of the hands on the central portion of each placenta from its fetal side and peripheral part was held by other fingers. This method makes each cotyledon more prominent. Cotyledons were counted from lower side of one end and going upward and again turning back to the lower end in the form of loop and this method was repeated until the end of placenta was reached. Total number of cotyledons was noted.

2.4 Data Collection Plan: There were three research variables; placental diameter $(\mathrm{cm})$, placental thickness $(\mathrm{mm})$ and number of cotyledons. All these were measured on ratio (numeric) scale. Category of hypertension was a factor/grouping variable with three attributes of normotensive, mild hypertensive and severe hypertensive, and was measured on ordinal scale.

\subsection{Data Analysis Plan}

2.5.1 Descriptive Statistics and Estimation of $\mathrm{Pa}$ rameters: The descriptive statistics were presented as mean, minimum, maximum, range and standard deviation for the three research variables for each group separately. Estimation of parameters for the population is presented as confidence interval $(\mathrm{Cl})$ at $95 \%$ confidence level $(\mathrm{CL})$ for mean, using an online statistical calculator. ${ }^{14}$

2.5.2 Hypotheses Testing: With three groups on ratio data, one way-ANOVA test was applied. It tells the significance of difference between the two groups with minimum and maximum means. We need the difference of mildly hypertensive group 2 to normotensive/ control group $1\left(\mathrm{H}_{01}, \mathrm{H}_{03} \& \mathrm{H}_{05}\right)$ and of severe hypertensive group 3 to normotensive/ control group $1\left(H_{02}, H_{04} \& H_{06}\right)$ separately, for which we applied post hoc Dunnett's t test ${ }^{15-16}$ (two sided) at alpha 0.05 . This multiple comparison test was developed by Canadian statistician Charles Dunnett in 1955 to compare each of a number of treatments with a single control. The updated table of critical values was published in 1964. Multiple comparisons to a control are also known as many-to-one comparisons. This test uses Student's t-statistic to compare each of the study group to a single control group. Data was analyzed by IBM SPSS Statistics for Windows, Version 22.0 (IBM Corp., Armonk, NY).

\section{RESULTS}

3.1 Descriptive Statistics and Estimation of Parameters: Table 3.1 shows the indices for the sample as sample statistics and indices of the population as $95 \% \mathrm{Cl}$ (confidence interval) of mean for the three research variables for each of the three groups. The comparison between the groups is based on confidence intervals. If there is overlap of confidence intervals, we say that these means are similar, otherwise different (smaller/ larger).

Descriptively, the mean placental diameter in group 2 i.e. $16.57 \mathrm{~cm}(95 \% \mathrm{Cl} 16.02-17.13)$ was lower than in group 1 i.e. $18.28 \mathrm{~cm}(95 \% \mathrm{Cl} 17.67-18.89)$. Similarly the mean placental diameter in group 3 i.e. $16.18 \mathrm{~cm}$ $(95 \% \mathrm{Cl} 15.68-16.67)$ was lower than in group 1 i.e. $18.28 \mathrm{~cm}(95 \% \mathrm{Cl} 17.67-18.89)$.

Descriptively, the mean placental thickness in group 2 i.e. $19.18 \mathrm{~mm}(95 \% \mathrm{Cl} 18.39-19.97)$ was similar to group 1 i.e. $19.34 \mathrm{~mm}(95 \% \mathrm{Cl} 18.29-20.39)$. Similarly the mean placental thickness in group 3 i.e. 17.60 $\mathrm{mm}(95 \% \mathrm{Cl} 16.60-18.60)$ was similar to group 1 i.e. $19.34 \mathrm{~mm}(95 \% \mathrm{Cl}$ 18.29-20.39).

Descriptively, the mean number of cotyledons in 
group 2 i.e. $14.08(95 \% \mathrm{Cl} 13.42-14.73)$ was similar to group 1 i.e. $14.42(95 \% \mathrm{Cl} 13.77-15.06)$. But the mean number of cotyledons in group 3 i.e. $13.16(95 \% \mathrm{Cl}$ 12.54-13.77) was lower than group 1 i.e. $14.42(95 \%$ Cl 13.78-15.06).

\subsection{Hypotheses Testing}

3.2.1 Placental diameter in control, mild hypertensive \& severe hypertensive women $\left(\mathrm{H}_{01}, \mathrm{H}_{02}\right)$ The difference of mean placental diameter between the control, mild hypertensive \& severe pregnancy induced hypertensive women was testified by inde- pendent samples One-Way ANOVA test. With p-value $<.0001$, the difference was statistically significant. (Table 3.2.1.1)

Now we would want to see if the mean placental diameter of mild hypertensive women is different from control $\left(\mathrm{H}_{01}\right)$ ? For this we applied post hoc Dunnett's t test (two sided). (Table 3.2.1.2)

With $\mathrm{p}$-value $<.0001, \mathrm{H}_{01}$ was proved to be false and hence rejected, showing that the mean placental diameter of mild PIH women is different from/ significantly lower than control.

Table 3.1: Descriptive statistics \& estimation of parameters of placental diameter, placental thickness \& number of cotyledons in control, mild hypertensive \& severe pregnancy induced hypertensive women in District D.I.Khan, Pakistan $(\mathbf{n}=150)$

\begin{tabular}{|c|c|c|c|c|c|c|c|c|c|}
\hline \multirow{2}{*}{ Variables } & \multirow{2}{*}{ Group } & \multirow{2}{*}{$\begin{array}{c}\text { Sample } \\
\text { Size }\end{array}$} & \multicolumn{5}{|c|}{ Sample Statistics } & \multicolumn{2}{|c|}{$95 \% \mathrm{Cl}$ of Mean } \\
\hline & & & Mean & Min. & Max. & Range & SD & Lower & Upper \\
\hline \multirow{3}{*}{$\begin{array}{l}\text { Placental } \\
\text { diameter } \\
(\mathrm{cm})\end{array}$} & Normotensive/ Control (Group 1) & 50 & 18.28 & 12.00 & 22.00 & 10.00 & 2.15 & 17.66 & 18.89 \\
\hline & Mild hypertensive (Group 2) & 50 & 16.57 & 13.50 & 20.50 & 7.00 & 1.94 & 16.02 & 17.13 \\
\hline & Severe hypertensive (Group 3) & 50 & 16.18 & 13.50 & 20.00 & 6.50 & 1.75 & 15.68 & 16.67 \\
\hline \multirow{3}{*}{$\begin{array}{l}\text { Placental } \\
\text { thickness } \\
(\mathrm{mm})\end{array}$} & Control (Group 1) & 50 & 19.34 & 11.0 & 26.40 & 15.40 & 3.70 & 18.29 & 20.39 \\
\hline & Mild hypertensive (Group 2) & 50 & 19.18 & 15.00 & 25.00 & 10.00 & 2.78 & 18.39 & 19.97 \\
\hline & Severe hypertensive (Group 3) & 50 & 17.60 & 10.00 & 22.60 & 12.60 & 3.52 & 16.59 & 18.60 \\
\hline \multirow{3}{*}{$\begin{array}{l}\text { Number of } \\
\text { Cotyledons }\end{array}$} & Control (Group 1) & 50 & 14.42 & 11 & 22 & 11 & 2.25 & 13.77 & 15.06 \\
\hline & Mild hypertensive (Group 2) & 50 & 14.08 & 9 & 19 & 10 & 2.30 & 13.42 & 14.73 \\
\hline & Severe hypertensive (Group 3) & 50 & 13.16 & 7 & 18 & 11 & 2.15 & 12.54 & 13.77 \\
\hline
\end{tabular}

Table 3.2.1.1: Comparison of mean placental diameter in control, mild \& severe pregnancy induced hypertensive women in District D.I.Khan, Pakistan $(n=150)$

\begin{tabular}{|c|c|c|c|c|c|c|c|c|}
\hline \begin{tabular}{|l|} 
Category of \\
hypertension
\end{tabular} & $\mathrm{N}$ & Mean Placental diameter $(\mathrm{cm})$ & & Sum of Squares & d.f. & Mean Square & $\mathrm{F}$ & $p$-value \\
\hline Group 1 & 50 & 18.28 & \multirow{2}{*}{$\begin{array}{c}\text { Between } \\
\text { Groups }\end{array}$} & \multirow{2}{*}{125.436} & \multirow{2}{*}{2} & \multirow{2}{*}{62.718} & \multirow{3}{*}{16.355} & \multirow{3}{*}{$<.0001$} \\
\hline Group 2 & 50 & 16.57 & & & & & & \\
\hline Group 3 & 50 & 16.18 & $\begin{array}{l}\text { Within } \\
\text { Groups }\end{array}$ & 563.719 & 147 & 3.835 & & \\
\hline Total & 150 & 17.01 & & 689.155 & 149 & \multicolumn{3}{|c|}{ One-Way ANOVA } \\
\hline
\end{tabular}

Table 3.2.1.2: Mean placental diameter in mild pregnancy induced hypertensive versus normotensive/ control women in District D.I.Khan, Pakistan $(n=100)$

\begin{tabular}{|c|c|c|c|c|c|c|}
\hline \multicolumn{5}{|c|}{ Mean placental diameter $(\mathrm{cm})$} & \multirow{2}{*}{ Stand. Error } & \multirow{2}{*}{ p-value } \\
\hline \multirow[b]{2}{*}{ Control $(n 1=50)$} & \multirow[b]{2}{*}{ Mild hypertensive $(\mathrm{n} 2=50)$} & \multirow[b]{2}{*}{ Difference of means } & \multicolumn{2}{|c|}{$95 \% \mathrm{Cl}$ of difference } & & \\
\hline & & & Lower & Upper & \multicolumn{2}{|c|}{$\begin{array}{c}\text { Dunnett's t test at alpha } \\
.05\left(\mathrm{H}_{01} \text { rejected }\right)\end{array}$} \\
\hline 18.28 & 16.57 & 1.71 & -0.8352 & 2.5848 & 0.39165 & $<.0001$ \\
\hline
\end{tabular}


Now we would want to see it the mean placental diameter of severe pregnancy induced hypertensive women is different from control $\left(\mathrm{H}_{02}\right)$ ? For this we applied post hoc Dunnett's t test (two sided). (Table 3.2.1.3)

With $\mathrm{p}$-value $<.0001, \mathrm{H}_{02}$ was proved to be false and hence rejected, showing that the mean placental diameter of sever PIH women is different from/ significantly lower than control.

3.2.2 Placental thickness in control, mild hypertensive \& severe pregnancy induced hypertensive women $\left(\mathrm{H}_{03}, \mathrm{H}_{04}\right)$

The difference of mean placental thickness between the control, mild hypertensive \& severe hypertensive women was testified by independent samples OneWay ANOVA test. With p-value .018, the difference was statistically significant. (Table 3.2.2.1)
Now we would want to see if the mean placental thickness of mild hypertensive women is different from control $\left(\mathrm{H}_{03}\right)$ ? For this we applied post hoc Dunnett's t test (two sided). (Table 3.2.2.2)

With $\mathrm{p}$-value $.957, \mathrm{H}_{03}$ was proved to be true and hence accepted, showing that the mean placental thickness of mild hypertensive women is similar to control.

Now we would want to see it the mean placental thickness of severe hypertensive women $\left(\mathrm{H}_{04}\right)$ is different from control (normal)? For this we applied post hoc Dunnett's t test (two sided).

(Table 3.2.2.3)

With $\mathrm{p}$-value $.019, \mathrm{H}_{04}$ was proved to be false and hence rejected, showing that the mean placental thickness of severe hypertensive women was significantly lower than control.

Table 3.2.1.3: Mean placental diameter in severe pregnancy induced hypertensive women versus normotensive/ control women in District D.I.Khan, Pakistan $(n=150)$

\begin{tabular}{|c|c|c|c|c|c|c|}
\hline \multicolumn{4}{|c|}{ Mean placental diameter $(\mathrm{cm})$} & \multirow{2}{*}{ Stand. Error } & p-value \\
\hline \multirow{2}{*}{ Control $(\mathrm{n} 1=50)$} & $\begin{array}{c}\text { Severe hypertensive } \\
(\mathrm{n} 3=50)\end{array}$ & Difference of means & \multicolumn{2}{|c|}{$95 \% \mathrm{Cl}$ of difference } & & \multicolumn{2}{|c|}{\begin{tabular}{c} 
Lower \\
\cline { 3 - 5 }
\end{tabular}} & & Upper & \multicolumn{2}{|c|}{$\begin{array}{c}\text { Dunnett's t test at alpha } \\
.05\left(\mathrm{H}_{02} \text { rejected }\right)\end{array}$} \\
\hline 18.28 & 16.18 & 2.10 & 1.2332 & 2.9828 & 0.39165 & $<.0001$ \\
\hline
\end{tabular}

Table 3.2.2.1: Comparison of mean placental thickness in control, mild \& severe pregnancy induced hypertensive women in District D.I.Khan, Pakistan $(n=150)$

\begin{tabular}{|c|c|c|c|c|c|c|c|c|}
\hline $\begin{array}{l}\text { Category of } \\
\text { hypertension }\end{array}$ & $\mathrm{N}$ & $\begin{array}{c}\text { Mean Placental thick- } \\
\text { ness }(\mathrm{mm})\end{array}$ & & $\begin{array}{l}\text { Sum of } \\
\text { Squares }\end{array}$ & d.f. & $\begin{array}{l}\text { Mean } \\
\text { Square }\end{array}$ & $\mathrm{F}$ & $p$-value \\
\hline Group 1 & 50 & 19.34 & Between & 93.191 & 2 & 46.595 & \multirow{3}{*}{4.128} & \multirow{3}{*}{.018} \\
\hline Group 2 & 50 & 19.18 & Groups & & & & & \\
\hline Group 3 & 50 & 17.60 & Groups & 1659.192 & 147 & 11.287 & & \\
\hline Total & 150 & 18.71 & & 1752.383 & 149 & \multicolumn{3}{|c|}{ One-Way ANOVA } \\
\hline
\end{tabular}

Table 3.2.2.2: Mean placental thickness in mild pregnancy induced hypertensive women versus normotensive/ control women in District D.I.Khan, Pakistan $(n=100)$

\begin{tabular}{|c|c|c|c|c|c|c|}
\hline \multicolumn{5}{|c|}{ Mean placental thickness $(\mathrm{cm})$} & \multirow{2}{*}{ Stand. Error } & \multirow{2}{*}{$\mathrm{p}$-value } \\
\hline \multirow[b]{2}{*}{ Control $(n 1=50)$} & \multirow{2}{*}{$\begin{array}{l}\text { Mild hypertensive } \\
\quad(\mathrm{n} 2=50)\end{array}$} & \multirow[b]{2}{*}{ Difference of means } & \multicolumn{2}{|c|}{$95 \% \mathrm{Cl}$ of difference } & & \\
\hline & & & Lower & Upper & \multicolumn{2}{|c|}{$\begin{array}{c}\text { Dunnett's t test at alpha } \\
.05\left(\mathrm{H}_{03} \text { accepted }\right)\end{array}$} \\
\hline 19.34 & 19.18 & .16 & -1.6648 & 1.3368 & 0.67192 & .957 \\
\hline
\end{tabular}

Table 3.2.2.3: Mean placental thickness in severe pregnancy induced hypertensive women versus normotensive/ control women in District D.I.Khan, Pakistan $(n=100)$

\begin{tabular}{|c|c|c|c|c|c|c|}
\hline \multicolumn{5}{|c|}{ Mean placental thickness $(\mathrm{cm})$} & \multirow{2}{*}{ Stand. Error } & \multirow{2}{*}{$\mathrm{p}$-value } \\
\hline \multirow[b]{2}{*}{ Control $(n 1=50)$} & \multirow{2}{*}{$\begin{array}{l}\text { Severe hypertensive } \\
\quad(\mathrm{n} 2=50)\end{array}$} & \multirow[b]{2}{*}{ Difference of means } & \multicolumn{2}{|c|}{$95 \% \mathrm{Cl}$ of difference } & & \\
\hline & & & Lower & Upper & \multicolumn{2}{|c|}{$\begin{array}{l}\text { Dunnett's } t \text { test at alpha } \\
.05\left(\mathrm{H}_{04} \text { rejected }\right)\end{array}$} \\
\hline 19.34 & 17.60 & 1.74 & 0.2472 & 3.2428 & 0.67192 & .019 \\
\hline
\end{tabular}


Table 3.2.3.1: Comparison of mean number of cotyledons in control, mild \& severe pregnancy induced hypertensive women in District D.I.Khan, Pakistan $(n=150)$

\begin{tabular}{|c|c|c|c|c|c|c|c|c|}
\hline Category of hypertension & $\mathrm{N}$ & Number of cotyledons & & Sum of Squares & d.f. & Mean Square & $\mathrm{F}$ & $p$-value \\
\hline Group 1 & 50 & 14.42 & \multirow{2}{*}{$\begin{array}{c}\text { Between } \\
\text { Groups }\end{array}$} & \multirow{2}{*}{42.493} & \multirow{2}{*}{2} & \multirow{2}{*}{21.247} & \multirow{3}{*}{4.240} & \multirow{3}{*}{.016} \\
\hline Group 2 & 50 & 14.08 & & & & & & \\
\hline Group 3 & 50 & 13.16 & \begin{tabular}{|l|} 
Within \\
Groups \\
\end{tabular} & 736.580 & 147 & 5.011 & & \\
\hline Total & 150 & 13.88 & & 779.073 & 149 & \multicolumn{3}{|c|}{ One-Way ANOVA } \\
\hline
\end{tabular}

Table 3.2.3.2: Mean number of cotyledons in mild pregnancy induced hypertensive women versus normotensive/ control women in District D.I.Khan, Pakistan $(n=100)$

\begin{tabular}{|c|c|c|c|c|c|c|}
\hline \multicolumn{5}{|c|}{ Mean number of cotyledons } & \multirow{2}{*}{ Stand. Error } & \multirow{2}{*}{$\mathrm{p}$-value } \\
\hline \multirow[b]{2}{*}{ Control $(n 1=50)$} & \multirow[b]{2}{*}{ Mild hypertensive $(\mathrm{n} 2=50)$} & \multirow[b]{2}{*}{ Difference of means } & \multicolumn{2}{|c|}{$95 \% \mathrm{Cl}$ of difference } & & \\
\hline & & & Lower & Upper & \multicolumn{2}{|c|}{$\begin{array}{c}\text { Dunnett's t test at alpha } \\
.05\left(\mathrm{H}_{05} \text { accepted }\right)\end{array}$} \\
\hline 14.42 & 14.08 & 0.34 & -0.6599 & 1.399 & 0.44769 & .666 \\
\hline
\end{tabular}

Table 3.2.3.3: Mean number of cotyledons in severe pregnancy induced hypertensive women versus normotensive/ control women in District D.I.Khan, Pakistan $(n=100)$

\begin{tabular}{|c|c|c|c|c|c|c|}
\hline \multicolumn{5}{|c|}{ Mean number of cotyledons } & \multirow{2}{*}{ Stand. Error } & \multirow{2}{*}{$\mathrm{p}$-value } \\
\hline \multirow[b]{2}{*}{ Control $(n 1=50)$} & \multirow[b]{2}{*}{ Severe hypertensive $(n 3=50)$} & \multirow[b]{2}{*}{ Difference of means } & \multicolumn{2}{|c|}{$95 \% \mathrm{Cl}$ of difference } & & \\
\hline & & & Lower & Upper & \multicolumn{2}{|c|}{$\begin{array}{c}\text { Dunnett's } t \text { test at alpha } \\
.05\left(\mathrm{H}_{06} \text { rejected }\right)\end{array}$} \\
\hline 14.42 & 13.16 & 1.26 & .2601 & 2.2599 & 0.47769 & .011 \\
\hline
\end{tabular}

3.2.3 Number of cotyledons in control, mild hypertensive \& severe pregnancy induced hypertensive women $\left(\mathrm{H}_{05}, \mathrm{H}_{06}\right)$

The difference of mean number of cotyledons between the control, mild hypertensive \& severe hypertensive women was testified by independent samples One-Way ANOVA test. With p-value .016, the difference was statistically significant. (Table 3.2.3.1) Now we would want to see if the mean number of cotyledons of mild hypertensive women is different from control $\left(\mathrm{H}_{05}\right)$ ? For this we applied post hoc Dunnett's t test (two sided). (Table 3.2.3.2)

With $\mathrm{p}$-value .666, $\mathrm{H}_{05}$ was proved to be true and hence accepted, showing that the mean number of cotyledons of mild hypertensive women was as same as control.

Now we would want to see it the mean number of cotyledons of severe hypertensive women is different from control $\left(\mathrm{H}_{06}\right)$ ? For this we applied post hoc Dunnett's t test (two sided). (Table 3.2.3.3)

With p-value .011, $\mathrm{H}_{06}$ was proved to be false and hence rejected, showing that the mean number of cotyledons of sever hypertensive women were different from/ significantly lower than control.

\section{DISCUSSION}

4.1 Placental diameter in control, mild hypertension \& severe hypertension $\left(\mathrm{H}_{01}, \mathrm{H}_{02}\right)$

Descriptively, our study showed that the mean placental diameter $16.57 \mathrm{~cm}(95 \% \mathrm{Cl} 16.02-17.13)$ in mild pregnancy induced hypertension (PIH) was lower than $18.28 \mathrm{~cm}(95 \% \mathrm{Cl} 17.67-18.89)$ in control/ normotensive women. The difference was statistically significant as verified by two sided post hoc Dunnett's t test ( $p$-value <.0001). (Tables 3.1 \& 3.2.1.2)

Descriptively, our study showed that the mean placental diameter $16.18 \mathrm{~cm}(95 \% \mathrm{Cl} 15.68-16.67)$ in severe $\mathrm{PIH}$ was lower than $18.28 \mathrm{~cm}(95 \% \mathrm{Cl}$ 17.67-18.89) in control/ normotensive women. The difference was statistically significant as verified by two sided post hoc Dunnett's t test ( $p$-value <.0001). (Tables 3.1 \& 3.2.1.3)

Similar to ours study, Baloch, et al. ${ }^{3}$ from Hyderabad, Pakistan in year 2012, showed that mean placental diameter $15.82 \pm 0.92 \mathrm{~cm}$ in $\mathrm{PIH}(\mathrm{n}=40)$ was lower than $16.39 \pm 1.14 \mathrm{~cm}$ in control/ normotensive women $(n=40)(p<.05)$.

Likewise, Goswami, et al. ${ }^{17}$ from Bhavnagar, Gujarat, India in year 2016, showed that mean placental diameter $14.5 \mathrm{~cm}$ in $\mathrm{PIH}(\mathrm{n}=50)$ was lower than 17.5 $\mathrm{cm}$ in normotensive women $(n=50)$ with significant difference.

Likewise, Agrawal, et al. ${ }^{18}$ from Rewa, Madhya Pradesh, India for the period from Dec. 1, 2015 to June 30,2017 , showed that mean placental diameter $14.12 \pm 1.83 \mathrm{~cm}$ in $\mathrm{PIH}(\mathrm{n}=100)$ was lower than $16.60 \pm 1.78 \mathrm{~cm}$ in normotensive women $(n=100)$ $(p<.001)$. 
Likewise, Chhatwal, et al. ${ }^{19}$ from Dehradun, Uttarakhand, India in 2018 showed that mean placental diameter $15.23 \pm 2.93 \mathrm{~cm}$ in PIH $(n=42)$ was lower than $18.63 \pm 4.25 \mathrm{~cm}$ in normotensive women $(n=42)$ $(\mathrm{t}=4.276, \mathrm{p}<.001)$.

Contrary to our study is report by Khaleel, et al. ${ }^{20}$ from Duhok, Kurdistan Region, Iraq from Feb. 27 to Oct. 1, 2018, showing that mean placental diameter $18.56 \pm 2.233 \mathrm{~cm}$ in gestational hypertension $(n=48)$ was similar to $19.2 \pm 2.005 \mathrm{~cm}$ in normotensive women $(n=25)(p=.235)$.

4.2 Placental thickness in control, mild hypertension \& severe hypertension $\left(\mathrm{H}_{03}, \mathrm{H}_{04}\right)$

Descriptively, our study showed that the mean placental thickness $19.18 \mathrm{~mm}(95 \% \mathrm{Cl} 18.39-19.97)$ in mild $\mathrm{PIH}$ was similar to $19.34 \mathrm{~mm}(95 \% \mathrm{Cl} 18.29-20.39)$ in normotensive women. The difference was statistically non-significant as verified by two sided post hoc Dunnett's t test ( $p$-value=.957). (Tables 3.1 \& 3.2.2.2)

Descriptively, our study showed that the mean placental thickness in sever PIH 17.60 (95\% Cl 16.60-18.60) $\mathrm{mm}$ was lower than $19.34 \mathrm{~mm}(95 \% \mathrm{Cl} 18.29-20.39)$ in normotensive women. The difference was statistically significant as verified by two sided post hoc Dunnett's $t$ test $(p$-value=.019). (Tables 3.1 \& 3.2.2.3)

Baloch, et al. ${ }^{3}$ from Hyderabad, Pakistan in year 2012 , showed that mean placental thickness $20.4 \pm 2.2 \mathrm{~mm}$ in $\mathrm{PIH}(\mathrm{n}=40)$ was lower than $21.1 \pm 3.1 \mathrm{~mm}$ in control/ normotensive women $(n=40)(p<.05)$.

Goswami, et al. ${ }^{17}$ from Bhavnagar, Gujarat, India in year 2016, showed that mean placental thickness $22 \mathrm{~mm}$ in PIH $(\mathrm{n}=50)$ was lower than $26 \mathrm{~mm}$ in normotensive women $(n=50)$ with significant difference.

Agrawal, et al. ${ }^{18}$ from Rewa, Madhya Pradesh, India for the period from Dec. 1, 2015 to June 30, 2017, showed that mean placental thickness $21.5 \pm 3.9$ $\mathrm{mm}$ in PIH $(n=100)$ was lower than $25.4 \pm 3.5 \mathrm{~mm}$ in normotensive women $(n=100)(p<.001)$.

Chhatwal, et al. ${ }^{19}$ from Dehradun, Uttarakhand, India in 2018 reported that mean placental thickness $19.1 \pm 4.7$ $\mathrm{cm}$ in PIH $(\mathrm{n}=42)$ was similar to $21.0 \pm 5.2 \mathrm{~cm}$ in normotensive women $(n=42)(t=1.806, p<.075)$.

Khaleel, et al. ${ }^{20}$ from Duhok, Kurdistan Region, Iraq from Feb. 27 to Oct. 1, 2018, showed that mean placental thickness $21.37 \pm 4.447 \mathrm{~mm}$ in gestational hypertension $(n=48)$ was similar to $20.84 \pm 2.46 \mathrm{~mm}$ in normotensive women $(n=25)(p=.235)$.

4.3 Number of cotyledons in control, mild hypertension \& severe hypertension $\left(\mathrm{H}_{05}, \mathrm{H}_{06}\right)$

Descriptively, the mean number of cotyledons 14.08 $(95 \% \mathrm{Cl} 13.42-14.73)$ in mild PIH was similar to 14.42 (95\% Cl 13.77-15.06) in control/ normotensive women. The difference was statistically non-significant as verified by two sided post hoc Dunnett's $t$ test ( $p$-value $=.666)$. (Tables $3.1 \&$ 3.2.3.2)

Descriptively, the mean number of cotyledons 13.16
(95\% Cl 12.54-13.77) in severe PIH was lower than 14.42 (95\% Cl 13.78-15.06) in control/ normotensive women. The difference was statistically significant as verified by two sided post hoc Dunnett's t test ( $p$-value $=.011)$. (Tables $3.1 \&$ 3.2.3.3)

Baloch, et al. ${ }^{3}$ from Hyderabad, Pakistan in year 2012, showed that mean number of cotyledons $16.92 \pm 0.9$ in $\mathrm{PIH}(\mathrm{n}=40)$ was lower than $17.10 \pm 0.98$ in control/ normotensive women $(n=40)(p<.05)$.

Goswami, et al. ${ }^{17}$ from Bhavnagar, Gujarat, India in year 2016, showed that mean number of cotyledons 15 in PIH $(n=50)$ was lower than 19 in normotensive women $(n=50)$ with significant difference.

Nahar, et al. ${ }^{21}$ from Mymensingh Division, Bangladesh in year 2013, showed that mean number of cotyledons 15.39 in $\mathrm{PIH}(\mathrm{n}=40)$ was lower than 17.40 in normotensive women $(n=40)$ with significant difference $(p<.001)$.

Khaleel, et al. ${ }^{20}$ from Duhok, Kurdistan Region, Iraq from Feb. 27 to Oct. 1, 2018, reported that mean number of cotyledons $16.72 \pm 4.551$ in gestational hypertension $(n=48)$ was similar to $17.64 \pm 4.536$ in normotensive women $(n=25)(p=.420)$.

4.4 Important Note: We have adopted the organization, format and logical flow of "Marwat's Logical Trajectory of Research Process". Here are few studies published in this journal on this format. $22-25$

\section{CONCLUSION}

In mild pregnancy induced hypertension $(\mathrm{PIH})$, placental diameter was lower than normotensives, while placental thickness and number of cotyledons were similar to normotensives. In severe pregnancy induced hypertension, placental diameter, placental thickness and number of cotyledons were all lower than normotensives. It is concluded from the present study that in mild $\mathrm{PIH}$, the development of placenta is mildly affected, while in severe PIH, the development of placenta is severely affected.

Acknowledgment: We all authors highly acknowledge the permission by Dr. Muhammad Marwat (marwatmuhammad@mail.com) to adopt his trajectory of research process. He has analyzed the data for us and has critically reviewed our manuscript.

\section{REFERENCES}

1. Londhe PS, Mane AB. Morphometric study of placenta and its correlation in normal and hypertensive pregnancies. Int J Pharma Bio Sci 2011; 2(4):429-7.

2. Knofler M, Pollheimer J. Human placental trophoblast invasion and differentiation a particular focus on Wnt signaling. Front Genet 2013;4(190):1-14. https://doi. org/10.3389/fgene.2013.00190

3. Baloch $\mathrm{AH}$, Memon SF, Ansari AK. Comparison of placentae from hypertension associated pregnancies and normal pregnancies. J Liaqat Uni Health Med Sci 2012 April;11(1):3-6.

4. Kvåle $G$, Olsen $B E$, Hinderaker SG, Ulstein $M$, Bergsjø P. Maternal deaths in developing countries: 
A preventable tragedy [review article]. Norsk Epidemiologi 2005; 15(2):141-9. https://doi.org/10.5324/ nje.v15i2.212

5. Backes $\mathrm{CH}$, Markham K, Moorehead P, Cordero L, Nankervis CA, Giannone PJ. Maternal preeclampsia and neonatal outcomes. J Pregnancy 2011;1-7. https://doi.org/10.1155/2011/214365

6. Riaz S, Habib S, Jabeen A. Frequency of maternal mortality and morbidity in pregnancy induced hypertension. J Ayub Med Coll Abbottabad 2011; 23(4):61-3.

7. Anorlu RI, Odum CU. Risk factors for pre-eclampsia in Lagos, Nigeria. Aus N Z J Obstet Gynaecol 2005 Aug; 45:78-82. https://doi.org/10.1111/j.1479828X.2005.00411.x

8. Akhtar F, Ferdousi R, Sultana R. Gross morphological variation in preterm placenta in gestational diabetes mellitus and pregnancy induced hypertension. J Enam Med Coll 2011; 1(2):71-5. https://doi. org/10.3329/jemc.v1i2.11466

9. Kishwara S, Ara S, Rayhan KA, Begum M. Morphological changes of placenta in preeclampsia. Bangladesh J Anat 2009; 7(1):49-54. https://doi.org/10.3329/bja. v7i1.3026

10. NIC guideline [NG 133]. Hypertension In pregnancy: diagnosis and management. [published 2019 Jun 25, cited 2020 July 14]. Available at: https://www.nice.org. uk/guidance/ng133

11. Hargitai B, Marton T, Cox PM. Examination of human placenta. J Clin Pathol 2004; 57:785-92. https://doi. org/10.1136/jcp.2003.014217

12. Un Nisa S, Shaikh A A, Kumar R. Maternal and fetal outcomes of pregnancy-related hypertensive disorders in a tertiary care hospital in Sukkur, Pakistan. Cureus 2019 Aug 28;11(8): e5507. https://doi. org/10.7759/cureus.5507

13. Raosoft ${ }^{\circledR}$ sample size calculator. [accessed 2020 May 14]. Available at: http://www.raosoft.com/samplesize.html

14. Jeremy Stangroom. Single-Sample Confidence Interval Calculator. Social Science Statistics. [accessed 2020 Apr 24]. Available at: https://www.socscistatistics.com/confidenceinterval/default2.aspx

15. Dunnett CW. A multiple comparison procedure for comparing several treatments with a control. J American Statistical Assoc 1955; 50(272): 1096-1121. https://doi.org/10.1080/01621459.1955.10501294

16. Dunnett C W. New tables for multiple comparisons with a control. Biometrics 1964 Sep; 20(3): 482-91. http://www.jstor.org/stable/2528485
17. Goswami P, Lata H, Memon S, Khaskheli LB. Excessive placental calcification observed in PIH patients and its relation to fetal outcome. J Liaqat Uni Health Med Sci 2012 Dec; 11(03):143-8.

18. Agrawal P, Agrawal SK, Singh S. A comparative study on placental changes in uncomplicated pregnancies with pre-eclamptic women. J Med Sci Clin Res 2018; 6(2):1291-6. https://doi.org/10.18535/jmscr/v6i2.203

19. Chhatwal J, Chaudhary DN, Chauhan N. Placental changes in hypertensive pregnancy: a comparison with normotensive pregnancy. Int J Reprod Contracept Obstet Gynecol 2018; 7:3808-13. https://doi. org/10.18203/2320-1770.jircog20183799

20. Khaleel GH, Barwari SSM. Placentas changes in gestational hypertensive women in Duhok. Duhok Medical Journal 2019 May; 13(1):96-11. https://doi. org/10.31386/dmj.2019.13.1.10

21. Nahar L, Nahar K, Hossain MI, Jahan S, Rahman MM. Placental changes in pregnancy induced hypertension. Mymensingh Med J. 2013 Oct; 22(4):684-93.

22. Ghori MR, Khan H, Marwat M. Distribution of non-malignant hematological disorders by sex, age groups and type of disease based on bone marrow aspiration in population of Khyber Pakhtunkhwa, Pakistan. Gomal J Med Sci 2019 Apr-Jun; 17 (2): 29-36. https:// doi.org/10.46903/ gjms/17.02.1926

23. Ain N, Khan S, Marwat M, Khan N, Ahmad I, Ramzan $\mathrm{F}$, et al. Frequency, distribution and determinants of hypertension in adult stroke population of D.I.Khan Division, Pakistan. Gomal J Med Sci 2019 Jul-Sep; 17 (3):81-9. https://doi. org/10.46903/gjms/17.03.2076

24. Marwat M, Ahmad I, Ashiq F, Ali S, Zamir S, Rehman $\mathrm{MU}$, et al. Frequency, distribution and determinants of diabetes mellitus in adult acute coronary syndrome population of D.I.Khan Division, Pakistan. Gomal J Med Sci 2019 Oct-Dec; 17 (4):131-43. https://doi. org/10.46903/gjms/17.04.2106

25. Khalid MK, Ahmad I, Khan MA, Sharjeel M, Irfan M. Marwat M. Distribution of pediatric cataracts by sex, age groups, laterality, type and presentation in population of D.I.Khan District, Pakistan. Gomal J Med Sci 2019 Oct-Dec; 17 (3):123-30. https://doi. org/10.46903/gjms/17.04.2025

\section{CONFLICT OF INTEREST \\ Authors declare no conflict of interest. GRANT SUPPORT AND FINANCIAL DISCLOSURE None declared.}

\section{AUTHORS' CONTRIBUTION}

The following authors have made substantial contributions to the manuscript as under:

Conception or Design: $\quad$ SA, AA

Acquisition, Analysis or Interpretation of Data:

$$
\begin{aligned}
& \text { SA, SA, AA, JK, SY, UU } \\
& \text { SA, SA, AA, JK, SY, UU }
\end{aligned}
$$

Manuscript Writing \& Approval:

All the authors agree to be accountable for all aspects of the work in ensuring that questions related to the accuracy or integrity of any part of the work are appropriately investigated and resolved. 